\title{
A INFLUÊNCIA DA ORIENTAÇÃO POLÍTICA DOS PREFEITOS NA PROBABILIDADE DE IMPLEMENTAÇÃO DE INSTITUTOS FEDERAIS E CAMPI UNIVERSITÁRIOS EM TEMPOS DE REUNI
}

The Influence of Political Orientation of Mayors on the Likelihood of Implementation of Federal Institutes and University Camps in REUNI Times

\author{
Akauã Flores ARROYO \\ akaua777@gmail.com \\ Universidade Federal de Santa Catarina (UFSC) \\ Francis Carlo PETTERINI \\ petterini@gmail.com \\ Universidade Federal de Santa Catarina (UFSC)
}

\begin{abstract}
RESUMO
Objetivo: O presente trabalho tem como objetivo avaliar se as decisões de implementação das unidades educacionais do ensino técnico e superior (Institutos Federais e campi Universitários Federais) tiveram como um dos fatores decisivos a orientação política dos prefeitos dos municípios durante o período do primeiro governo petista (2003 a 2010). Para fazer a estimação foi usado um modelo probit bivariado (BIPROBIT) com o objetivo de mitigar os vieses de simultaneidade (e endogeniedade) decorrentes da correlação entre implantar um novo Instituto Federal e implantar um novo campus. Foram encontrados indícios de que houve um impacto significativo na probabilidade de concessão dos IFs devido à orientação política dos prefeitos, em todo o país exceto na região Nordeste, porém não foram encontrados indícios do impacto na implantação dos campi universitários em nenhum dos dois casos (com todo o país e sem a região Nordeste). Assim, o estudo conclui que a orientação política dos prefeitos pode ter influenciado na concessão dos IFs no período analisado.
\end{abstract}

PALAVRAS-CHAVE: Políticas Públicas. Biprobit. REUNI. Ensino superior. Ensino técnico.

\begin{abstract}
Objetive: The aim of this study is to evaluate if the decisions of implementation of the educational units of technical and higher education (Federal Institutes and Federal Universitys) had as a decisive factor, the political orientation of the mayors of the municipalities during the period of the first petist government (2003 to 2010). In order to make the estimation, a bivariate probit model (BIPROBIT) was used to mitigate the biases of simultaneity (and endogeneity) arising from the correlation between implanting a new Federal Institute and deploying a new campus. There were indications of a significant impact on the probability of granting IFs due to the political orientation of mayors, in all coutry except in Northeast reagion, but wasn't found evidences of the impact on the implantation of the Federal Universitys in neither case (all over the country and without the Northeast). Thus, the study concludes that the political orientation of mayors may have influenced the concession of the IFs in the analyzed period.
\end{abstract}

KEYWORDS: Public Policy. biprobit. REUNI. Higher Education. Technical Education.

Classificação JEL: C31; H41; H52

Recebido em: 18-05-2019. Aceito em: 07-01-2020. 


\section{INTRODUÇÃO}

O primeiro governo petista foi marcado por uma intensa criação e renovação de programas voltados à ampliação de unidades de ensino técnico e superior no país, como a retomada da expansão dos CEFETs e a criação do Plano de Desenvolvimento da Educação (PDE), que trouxe consigo o surgimento do programa de Reestruturação e Expansão das Universidades Federais (REUNI). Tais programas possibilitaram que, apenas nesse período (2003 a 2010), fossem inaugurados 214 novos IFs $^{1}$ e 126 novos campi universitários, conforme dados do Ministério da Educação (MEC)2.

É sabido que a estrutura política do primeiro governo petista era majoritariamente da coligação aliada ${ }^{3}$, principalmente dos partidos do PMDB e do próprio PT que eram os mais fortes no período, dado que, durante o período de implementação do plano, tanto o ministro da educação Fernando Haddad, quanto o seu antecessor Tarso Genro, eram membros do $\mathrm{PT}^{4}$, e a estrutura do Senado e do Congresso eram majoritariamente da coligação aliada durante todo o primeiro governo petista. De maneira mais detalhada, de 2003 até 2006 temos que $56,80 \%$ do Senado e $49,51 \%$ da Câmara dos Deputados eram compostos por representantes da coligação aliada (sendo $43,21 \%$ de todo o Senado e $32,56 \%$ de toda a Câmara compostos por membros exclusivamente do PT e do PMDB), e de 2007 até 2010 temos que $50,62 \%$ do Senado e $61,21 \%$ da Câmara eram membros da coligação aliada (sendo $30,86 \%$ de todo o Senado e $33,56 \%$ de toda a Câmara compostos por membros exclusivamente dos partidos do PT e do PMDB $)^{5}$. No tocante as prefeituras, conforme dados do Tribunal Superior Eleitoral(TSE) ${ }^{6}$ temos que na eleição de 2004 , cerca de $46,82 \%$ dos prefeitos eleitos eram da coligação aliada ao PT e cerca de $26,43 \%$ de todos os prefeitos eleitos eram apenas dos partidos do PT e do PMDB, sendo que o PMDB foi o

\footnotetext{
1 Os Institutos Federais (IFs) representam o conjunto dos Institutos Federais de Educação, Ciência e Tecnologia (IFETs); Centros Federais de Educação Tecnológica (CEFETs); Escolas Técnicas vinculadas às Universidades Federais; a Universidade Tecnológica Federal do Paraná; e o Colégio Pedro II.

2 Conforme MEC (2011).

${ }^{3}$ A coligação aliada ao PT era composta pelos partidos: PMDB, PP, PR, PSB, PDT, PSC, PC do B, PRB e PTC

${ }^{4}$ O mandato de Tarso Genro deu-se de 27/01/2004 a 29/07/2005, e o de Fernando Haddad deu-se de 29/07/2005 a 24/01/2012, conforme informações disponíveis em http://portal.mec.gov.br/institucional/galeriade-ministros.

${ }^{5}$ Conforme dados disponíveis em http://www.estadao.com.br/infograficos/politica,o-tamanho-dos-partidosnocongresso-nacional,281061.

${ }^{6}$ Disponível em: http://www.tse.jus.br/eleicoes/eleicoes-anteriores/eleicoes-2004/candidaturasvotacao-eresultados/resultados-das-eleicoes-2004
} 
partido que mais elegeu prefeitos (1060), Além disso, sabe-se que na segunda parte do plano de expansão (2007 a 2010) houve uma forte pressão dos governos regionais ao Governo Federal para que houvesse a concessão de um IFs ou um campus em sua região.

Diante deste cenário, questiona-se se a concessão dos IFs e dos campi universitários foi feita baseada apenas nas necessidades socioeconômicas das regiões em que foram implementadas, dado que, segundo o Ministério da Educação (MEC (2011)), municípios que apresentassem essas necessidades teriam prioridade na implantação das unidades, ou se a orientação política dos prefeitos também é uma variável relevante na escolha da concessão dos IFs e campi universitários. Caso encontra-se evidências a favor da hipótese de uma influência da orientação política na concessão dos IFs e campi, então teríamos um indicativo sobre como as decisões de investimento em educação são tomadas e como elas seriam ineficientes, pelo menos no período analisado. Com o intuito de responder a esta questão, estrutura-se este trabalho.

Para realizar a estimação, foram coletados os dados socioeconômicos (população e renda domiciliar percapita) dos municípios. do censo do IBGE 20107 . O partido político dos prefeitos foi obtido através de dados do TSE e o ano de inauguração de cada IFs e campus universitário foi coletado através de informações disponibilizadas pelo Ministério da Educação (MEC). Já a estimação foi realizada utilizando um modelo probit bivariado apenas com municípios que não possuíam nenhuma das duas unidades educacionais (IF ou/e campus) pois os municípios que já possuam um IF ou/e um campus antes de 2003 possuem características bem distintas do demais municípios. Com o uso dessa estimação encontrouse indícios do impacto da orientação política dos prefeitos (PT e PMDB) na probabilidade de concessão de um IF em todo o país, exceto na região Nordeste, porém essa influência não é estatisticamente significante no caso da concessão dos campi universitários.

Para cumprir o objetivo acima citado, o trabalho será divido em quatro seções: a primeira é composta por esta introdução. A segunda, por um apanhado histórico dos programas de criação de unidades das Educação Profissional e Tecnológica (EPT) e dos campi universitários, além uma apresentação do Plano de Desenvolvimento da Educação (PDE) através de dados do Ministério da Educação e da bibliografia nacional sobre o assunto, e uma breve apresentação dos impactos causados por esses campi e IFs na economia através dos efeitos-gasto e efeito-conhecimento. A terceira seção conterá toda a estratégia empírica para cumprir os objetivos citados a partir de um modelo probit bivariado,

${ }^{7}$ O censo de 2000 também foi utilizado para calcular o PIB per capita dos municípios 
além dos resultados obtidos e análise dos mesmos. A última seção conterá as considerações finais do trabalho ${ }^{8}$.

\section{REVISÃO BIBLIOGRÁFICA}

Esta seção apresenta, em suas duas primeiras subseções, a revisão bibliográfica referente à história de investimentos em EPT e no Ensino Superior através da bibliografia nacional sobre o assunto e também os seus aspectos normativos. A terceira subseção evidenciará os aspectos normativos do PDE e também dos programas do REUNI (Reestruturação e expansão das Universidades Federais) e do CEFET, iniciado no $1^{\circ}$ mandato do presidente Lula, cuja implementação nos dois mandatos do presidente Lula é o nosso objeto de análise.

Não foram encontrados trabalhos que avaliassem de uma maneira quantitativa se a expansão das universidades e dos IFs durante os mandatos do presidente Lula foi influenciada por decisões políticas adversas às questões socioeconômicas dos municípios. Os poucos trabalhos nacionais encontrados abordando o assunto com uma análise quantitativa estimavam o retorno econômico dos campi universitário e dos IFs na economia. Assim, a maioria dos trabalhos encontrados referiam-se aos aspectos sociais e normativos da política ao invés de quantificar o impacto econômico causado pelos mesmos. Dentre estes trabalhos quantitativos, exemplifica-se o trabalho de Rolim e Kureski (2010), que estimou um efeito-gasto na economia brasileira de $R \$ 1,90$ para cada $R \$ 1,00$ investido em um novo campus, utilizando-se de uma abordagem de matriz insumo-produto de Leontieff para estimar o multiplicador. Outro trabalho relevante é o de Barbosa, Petterini e Ferreira (2016) em que se estima se houve retorno de curto e longo prazo na economia devido à criação de um novo campus, através de um modelo de diferenças em diferenças aliado com um escore de pareamento com o objetivo de mitigar os vieses da análise. Neste trabalho, Barbosa, Petterini e Ferreira (2016) encontraram indicativos do impacto de "longo prazo" em municípios maiores e que já haviam recebido o campus no começo da política, e um impacto de "curto prazo" em municípios menores. Com isso, encontraram indicativos de que o tipo de efeito varia tanto com o tempo de "maturação" do mesmo, quanto com as

\footnotetext{
${ }^{8}$ Não é escopo deste trabalho uma análise das políticas de inclusão (PROUNI, PRONATEC, FIES e etc), as vagas criadas devido à política de expansão. Portanto, o presente trabalho tem como objetivo apenas um breve resgate histórico das políticas de expansão, além de uma breve análise da política implementada no período do Governo Lula além de uma análise empírica para a estimação do impacto da orientação política.
} 
idiossincrasias (população, estrutura econômica, porte econômico e etc) dos municípios, que favorecem a ampliação de um dos tipos de efeito, corroborando a teoria de Florax (1992) de que o efeito-conhecimento (longo prazo) é maior nos municípios que possuem mais habitantes.

Há uma importante diferença entre os efeitos gastos e conhecimento. O efeito-gasto é o efeito de curto prazo gerado logo após o gasto com o campus devido aos aumentos de demanda gerados por sua criação. Rolim e Kureski (2010), ilustram que o efeito-gasto pode ser separado em 3 efeitos: i) seria o chamado Efeito Direto (os gastos com professores, administração e etc); ii) o Efeito Indireto (os investimentos causados pela instalação do campus); iii) os Efeitos Induzidos (os gastos em consumo gerados pelo aumento da demanda decorrente da instalação do campus). Logo, conclui-se que o efeito-gasto é o efeito de curto prazo proveniente do aquecimento econômico local gerado pela implantação do campus. Quanto ao efeito-conhecimento, trata-se do efeito gerado pelo aumento da capacidade técnica da população (capital humano da população) que proporcionaria uma melhora da capacidade produtiva do setor produtivo e consequentemente uma melhora do crescimento econômico através do aumento do capital humano, possibilitando,inclusive, uma melhora das taxas de crescimento naturais, conforme os modelos de crescimento endógeno de Lucas (1988) e Romer (1990). Sendo assim, este seria o efeito de longo prazo (ROLIM; KURESKI, 2010; BARBOSA; PETTERINI; FERREIRA, 2016).

\subsection{Evolução Histórica da EPT}

A partir da invasão portuguesa, inicia-se o processo de escravização dos indígenas com o objetivo de trabalhar nas funções extrativistas. Durante o século XVI ocorreu o processo de substituição dos escravos indígenas pelos escravos africanos, sendo que o difícil acesso à terra pelos escravos os forçava a aceitar a escravatura, Apesar da Lei de terras de 1850 que possibilitava o acesso às terras pelos que pudessem compra-las ainda não foi possível amenizar a situação da escravatura no Brasil, devido às condições precárias em que os escravos estavam sujeitos. A chegada da Lei Áurea, em 1888, não resolveu o problema da população afrodescendente, pois eles acabaram ficando sem terra e sem "emprego" para poderem assegurar sua subsistência. Dadas estas características conjunturais, percebe-se que mesmo com o surgimento das primeiras indústrias no final do 
século XIX, não havia incentivos à criação de um Ensino Profissional e Tecnológico, se considerarmos o período desde 1500 até o final do século XIX (TAVARES, 2012).

Durante a Primeira República o ensino profissionalizante surge com o objetivo de atender a classe marginalizada pela sociedade à época, sendo estes os portadores de necessidades especiais, ex-escravos e órfãos. O anseio era reduzir os índices de criminalidade da época pois a indústria ainda estava em fase embrionária neste período. Portanto, a mesma ainda não demandava trabalhadores qualificados (TAVARES, 2012). Em 1909, através do decreto $N^{\circ} 7566$ de 23 de Setembro, as escolas de aprendizes artífices foram criadas pelo presidente Nilo Peçanha. As escolas tinham como objetivo a formação da classe operária, conforme Soares (1982): "A finalidade dessas escolas era a formação de operários e contramestres através de ensino pratico e conhecimentos técnicos necessários aos menores que pretendessem aprender um oficio"(SOARES, 1982, p.61).

Em 1927 há um marco decisivo para a posterior expansão das unidades de EPTs no país; o Congresso Nacional aprova o projeto Fidélis Reis que obriga o fornecimento de educação em ensino profissional em todo o país. A partir disso, ocorre uma rápida expansão do número de unidades de EPT no país, fazendo o seu número ir de cerca de um pouco mais de duas dezenas para mais de uma centena entre o período de 1929 até o começo da ditadura militar. Esta considerável expansão deve-se ao projeto nacional desenvolvimentista desenvolvido pelo Brasil desde o segundo governo Getúlio Vargas, que através da troca do modelo agro-exportador para um modelo voltado para a indústria nacional, necessitava da mão-de-obra qualificada proveniente destas unidades de EPT (CIAVATTA; RAMOS, 2012; TAVARES, 2012).

Dentre o período acima citado, vale a pena mencionar algumas medidas adotadas com objetivo de expansão dos IFs. A primeira foi a aprovação da chamada "Reforma Capanema" durante a segunda era Vargas (1937-1946), que remodela todo o ensino no país através das chamadas Leis Orgânicas. Nesta reforma houve a criação do SENAI e SENAC, através dos decretos n 4048, 8621 e 8622 respectivamente. A segunda medida foi a obrigatoriedade da igualdade entre o ensino médio e o ensino profissionalizante que aumentou a demanda dos jovens por esse tipo de curso (TAVARES, 2012).

Outro fator relevante refere-se a criação da Lei de Diretrizes e Bases da Educação Brasileira, que obrigava a profissionalização dos estudantes no ensino secundário, porém tal medida não foi efetiva pois haviam várias escolas que "fingiam"que passavam o ensino profissionalizante enquanto só passavam o ensino convencional. Com isso, a tentativa de 
unificação entre a educação convencional e a profissionalizante foi fracassada (TAVARES, 2012).

A partir da década de 1980 ocorreu um redirecionamento das unidades da EPTs para as áreas de telecomunicação, microeletrônica e informática devido aos impactos causados pela globalização. Além disso, com o advento da disparada inflacionária dos anos 1980 ocorreu um arrefecimento da expansão das EPTs, assim o plano de produzir "técnicos em larga escala" acabou não se concretizando nesse período, conforme MEC (2010):

Os anos de 1980 caracterizam-se por uma nova configuração da economia mundial, reconhecida como globalização - processo que vem acoplado à intensificação da aplicação das telecomunicações, da microeletrônica e da informática [...] No Brasil, esses anos oitenta e início dos anos noventa são também marcados pela disparada inflacionária, retração do crescimento e grande descontrole da economia, cenário que vem contrariar as expectativas que se projetaram quando da divulgação da meta "formação de técnicos em grande escala". A promulgação da Lei n0 7.044/827, que alterou dispositivos da Lei n0 5.692/71, referentes à obrigatoriedade da profissionalização. (MEC, 2010)

Na década de 1990 ocorreu a Reforma do Estado, marcada pelas terceirizações, inclusive de serviços públicos essenciais. Frente a este cenário, ocorreu um avanço do ensino privado que contribuiu pra que se fosse, paulatinamente, adotando um modelo em que a educação profissional se responsabilizava para a formação dos trabalhadores. Porém, o público alvo e o objetivo da criação das unidades da EPT não havia mudado em sua essência, ou seja, o público alvo continuava sendo os jovens e adultos com interesse em uma formação profissional porém, o problema da dualidade estrutural abordado por Kuenzer (2006) continuava presente neste período apoiado em três premissas apresentadas por Tavares (2012), sendo elas:

- Diminuir a taxa de ingressantes no ensino superior provenientes das escolas técnicas, de forma a manter uma oferta de profissionais.

- Diminuir os custos dos cursos técnicos, com o objetivo de reduzir os gastos da parte pública e possibilitar a manutenção de preços competitivos por parte do Ensino Privado.

- Diminuir o tempo de duração dos cursos técnicos, através de mudanças na estrutura de seus currículos de forma a colocar mais profissionais no mercado de trabalho em um menor período de tempo e também, facilitando a adaptação por parte das instituições de ensino privadas. 
A partir de 2003 inicia-se uma nova fase de expansão das unidades das EPT, com a eleição do presidente Lula. Neste momento há uma mudança de paradigma nos objetivos dessas unidades da EPT e também de sua forma organizacional através de programas que promoviam, com a da participação do Governo Federal, a expansão dessas unidades. Tal estágio será analisado na seção 2.3, juntamente com a expansão dos campus universitários neste período.

\subsection{Evolução Histórica do Ensino Superior Brasileiro}

No período colonial (principalmente nos séculos XVI a XVIII), o ensino superior no Brasil era bem incipiente, tendo como objetivo a formação da elite agrária e da classe dominante "burguesa", sendo os colégios jesuítas espalhados pelo país os que realizavam os cursos. A situação começou a mudar apenas por volta da segunda metade do século XVIII, quando o Marques de Pombal expulsou os jesuítas do império português e promoveu a reforma da Universidade de Coimbra em 1772, que gerou impactos na construção dos currículos do ensino superior no Brasil, conforme Souza (2012).

Ocorreram profundas transformações no ambiente escolar do Império com a implantação de novos currículos, novos métodos e novas estruturas escolares. No Brasil, ocorreu a completa desestruturação do sistema escolar, resultando na criação de cursos superiores estruturados no Rio de Janeiro, em 1776, pelos franciscanos e no Seminário de Olinda com o bispo Azevedo Coutinho, em 1798. Tais cursos foram criados nos moldes da Universidade de Coimbra reformada e formaram os precursores e os proclamadores da Independência do Brasil em 1822 (SOUZA, 2012, p.47).

Durante o século XIX (mais precisamente até o fim do Império em 1889), o ensino superior foi caracterizado como um ensino voltado para as profissões tradicionais, ao invés do formato que há atualmente. Porém, a partir do final do século XIX, a implementação da Constituição da República torna possível a descentralização do Ensino Superior por parte do Governo Federal.

Foi criado, então, o Sistema Educacional Paulista, pioneiro na implementação de Universidades Estaduais no Brasil. Este fato representa o ponto de inflexão no começo da mudança dos currículos que paulatinamente foram se tornando menos "profissionalizantes" e mais voltados para a área de pesquisa (SAMPAIO, 1991). Foram criadas 451 novas escolas de ensino superior entre 1900 até 1960 segundo Sampaio (1991 apud TEIXEIRA, 2005, p.7). 
Porém, a mudança decisiva ocorreu com a Reforma Universitária de 1968 (tendo como influência os acordos MEC-USAID), em que foram implementadas diversas alterações na estrutura do ensino superior no país, nesta reforma houve a "institucionalização" da carreira acadêmica e o começo de um modelo que permitia maiores ligações entre ensino e pesquisa. Além disso, foi dado início à criação dos cursos de pósgraduação, estimulando a criação de dispositivos que cumprissem este objetivo. Assim, contribuiu para a posterior ampliação dos programas de iniciação cientifica contudo, criou condições para que o Ensino Privado se instalasse no país, sendo esse "Ensino Privado" qualitativamente distinto dos programas federais, dado que visava a rápida formação de profissionais para o mercado de trabalho privado (MARTINS, 2009).

Após um arrefecimento do ensino superior na década de 1980, devido aos graves problemas econômicos que o país estava passando, dificultou-se a expansão dos campi federais, nesse período. Porém, houve um aumento significativo no número de campi estaduais. Na década de 1990, há uma retomada da criação de unidades do ensino superior devido ao aumento da demanda pelos cursos porém, a grande maioria das instituições criadas eram privadas, evidenciando a dificuldade do Governo Federal de se adaptar à nova demanda (MARTINS, 2000), conforme Martins (2000):

A expansão do ensino de graduação verificada nas últimas décadas foi, em grande parte, atendida e patrocinada pelo segmento privado. A rede pública, especialmente as instituições federais, cresceu em um ritmo mais lento se comparada ao setor privado, encontrando dificuldade para atender à ampliação da demanda"(MARTINS, 2000, p.57).

A partir nos anos 2000, principalmente a partir de 2003, ocorreu uma mudança de paradigma com a eleição do presidente Lula, em que há uma franca expansão do numero de campi federais no país, conforme dito na seção passada, tal expansão será abordada conjuntamente com a expansão dos IFs na seção a seguir.

\subsubsection{Expansão da Rede Federal das unidades de EPT e de Universidades Federais durante o Governo Lula}

Conforme já dito, a eleição do presidente Lula marcou uma mudança no paradigma no tocante a educação profissional e tecnológica. Conforme MEC (2011), a expansão dessas unidades de EPT agora tem como objetivo não apenas formar técnicos para o 
mercado de trabalho, mas também tornar o ensino técnico mais atrativo do que o ensino médio regular para a maioria dos jovens, além de incentivá-los a ficarem em sua cidade. Com isso, tem como objetivo a "formação de profissionais qualificados, fomentando o desenvolvimento regional e estimulando a permanência de profissionais qualificados no interior do Brasil"(MEC, 2011, p.2). Além do objetivo acima citado, essa expansão tinha como objetivo aumentar e consolidar o número de vagas de acesso ao ensino superior e ao ensino técnico através de um aumento da rede de Institutos Federais e Universidades Federais, assim, conseguindo potencializar a função social destas unidades, possibilitando um impacto positivo nos indicadores socioeconômicos (MEC, 2011).

Porém, conforme observado por Tavares (2012), tal reforma na parte dos IFs, teve seu início em 2005, com a mudança da lei de "criação"dos CEFETs, a Lei n 8948/94. Esta lei promovia a ampliação das Escolas Técnicas Federais, porém, as mesmas passariam a seguir o molde dos três CEFETS já existentes (o de MG, RJ e PR). Entretanto, havia um impeditivo na lei supracitada (no artigo $3^{\circ}$ ) que obrigava que a construção dos CEFETS fosse feita em parceria com outros órgãos (Estados, municípios, iniciativa privada e etc). Logo, com a vinda da lei $n^{\circ} 11195 / 05$, que retificava esse parágrafo do artigo, tornando a parceria preferencial, mas não obrigatória, possibilitou a expansão dos CEFETS (consequentemente dos IFs), por parte do

Governo Federal, de maneira mais autônoma. (TAVARES, 2012).

No tocante aos IFs, o seu programa de expansão iniciou-se por volta de 2005, conforme dito anteriormente, através do lançamento do Programa de Expansão da Rede Federal de Educação Profissional e Tecnológica no governo Lula. Esta expansão seria dividida inicialmente em duas fases (Fase 1: de 2005 a 2007 e Fase 2: de 2007 a 2010) porém, com a posterior eleição da presidente Dilma Rousseff em 2010, acabou sendo lançada uma terceira fase do programa com o objetivo de cumprir as metas das fases anteriores e expandir ainda mais a rede. Somente nesse período a criação de 64 novas unidades de ensino técnico estavam previstas, sendo esse valor maior do que a metade de todas as escolas feitas de 1909 até 2003 (120), ou seja, houve um aumento de mais de 50\% no número de unidades em apenas 3 anos. (TAVARES, 2012).

Na segunda fase (2007 a 2010) ocorreu uma expansão maior ainda dos IFs (conforme pode ser observado na Figura acima), apoiada no surgimento do PDE (Plano de 
Desenvolvimento da Educação) $)^{9}$ que se propunha a dar mais instrumentos para que o Governo Federal pudesse continuar com a expansão, segundo Haddad (2008):

O PDE, nesse sentido, pretende ser mais do que a tradução instrumental do Plano Nacional de Educação (PNE)[...]. É bem verdade[...] que o PDE também pode ser apresentado como plano executivo, como conjunto de programas que visam dar consequência às metas quantitativas estabelecidas naquele diploma legal [...] (HADDAD, 2008, p.7).

Assim, com esses facilitadores normativos aliados a uma crescente pressão dos governos regionais (inclusive dos municípios) sobre o Governo Federal, foram criados mais 150 Institutos Federais durante o período de 2007 a 2010. Desta forma, somam 214 novos IFs criados apenas no Governo Lula, baseados nas prioridades geográficas (redistribuir bem os centros geograficamente) e que estejam em harmonia com o governo regional (surgimento de parceiras ou uma reciclagem de estruturas existentes) (TAVARES, 2012).

Figura 1 - Número de IFs e campi novos criados, por ano, de 2003 a 2010

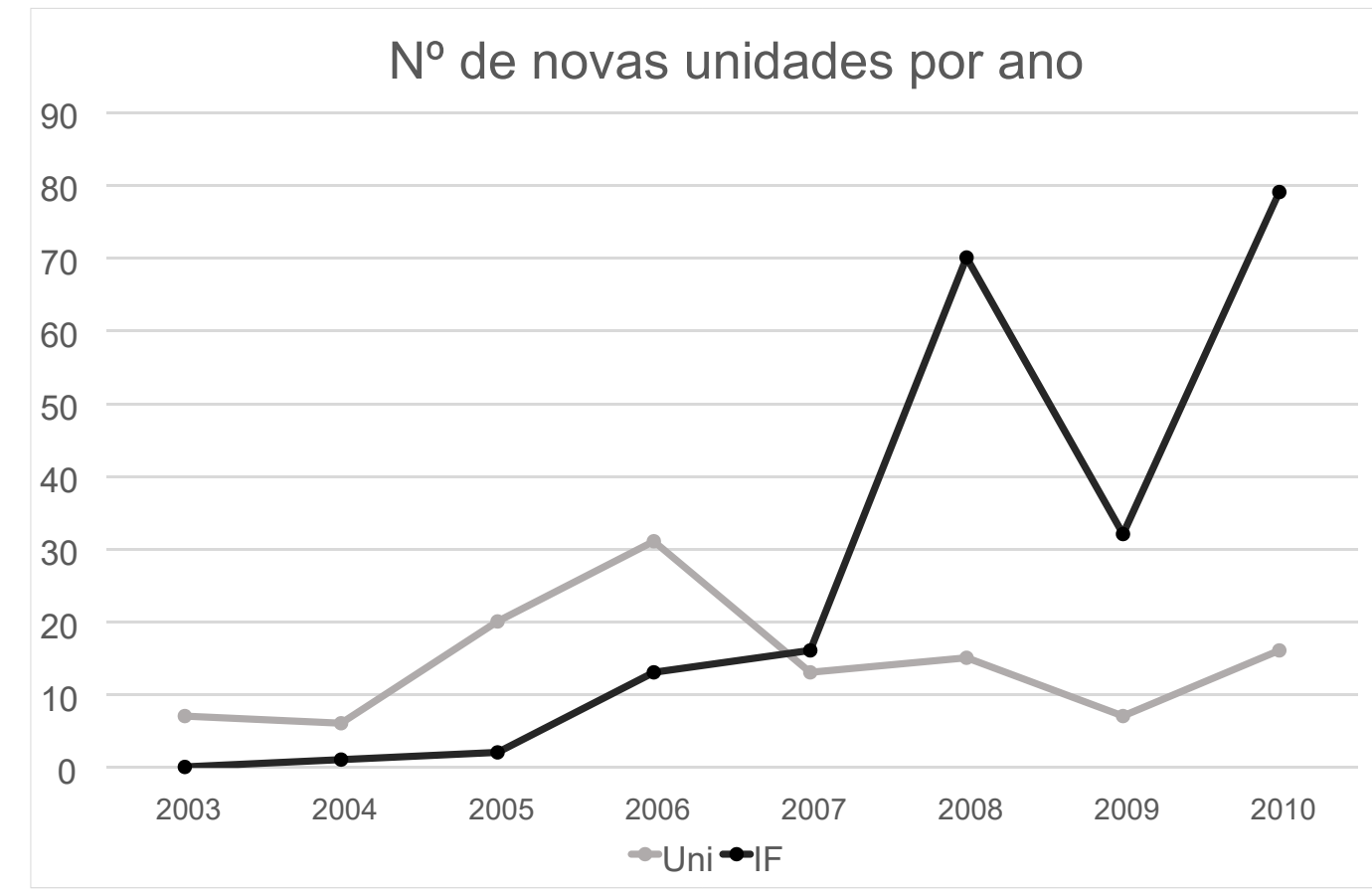

Fonte: Elaborado pelo autor a partir de dados do MEC

\footnotetext{
${ }^{9}$ Criado através do Decreto no 6094 de 24 de Abril de 2007
} 
Por conta disso, houve um elevado aumento no número de matriculas de 113 mil para 300 mil matrículas, cerca de 29 mil vagas foram ocupadas por professores e técnicos administrativos. De maneira similar, o orçamento total da Secretária de Ensino Médio e Tecnológico passou de $\mathrm{R} \$ 1,1$ bilhão para $\mathrm{R} \$ 4,4$ bilhões em apenas 8 anos, sendo que o valor de $\mathrm{R} \$ 1,1$ bilhão de 2003 englobava o orçamento destinado também ao ensino médio, enquanto o de 2010 era exclusivo ao ensino técnico (MEC/SETEC,2011).

Os centros foram distribuídos pelo Brasil conforme a Figura 2.

A Figura 2 temos que os marcadores mais claros são os IFs criados antes de 2003, e os marcadores mais escuros são os IFs criados de 2003 a 2010. Analisando-a percebese que há uma grande concentração dos novos IFs (2003 a 2010) nas regiões Sul e Sudeste (provavelmente por aspectos econômicos e populacionais) e na região Nordeste (provavelmente por aspectos sociais e populacionais). Contudo, geograficamente falando, parece haver uma certa carência de IFs nos Estados do Norte e Centro-Oeste.

Figura 2 - IFs implantados até 2010

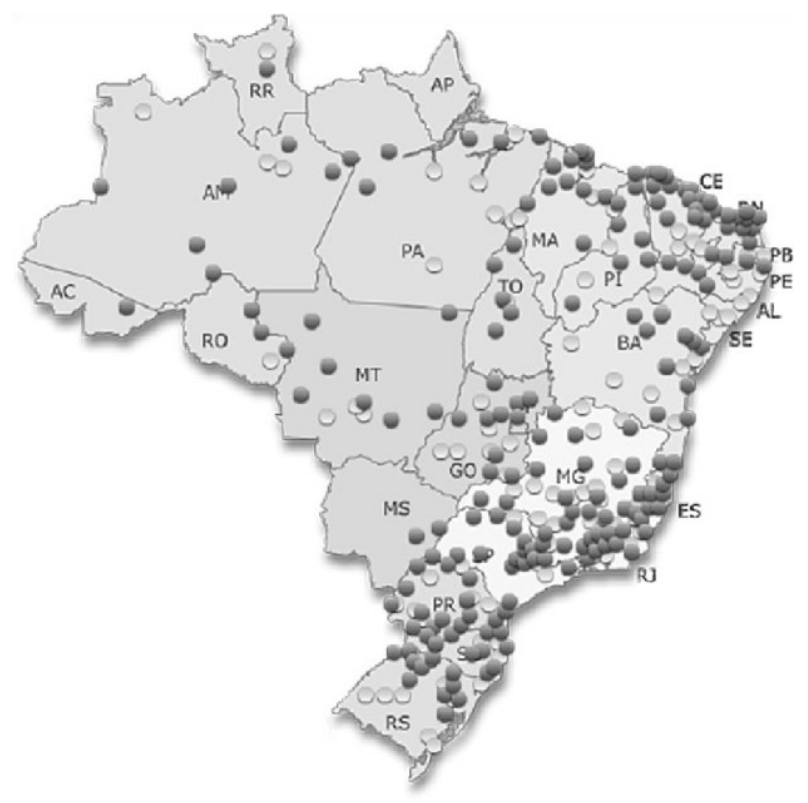

Fonte: MEC (2011) 
Quanto aos campi universitários, houve uma expansão já nos anos iniciais do Governo Lula. Entretanto, a fase de maior expansão foi a partir de 2005, posteriormente auxiliada pela criação do Plano de Reestruturação e Expansão das Universidades Federais (REUNI) pelo Decreto $n^{\circ}$ 6096/2007. De acordo com MEC (2013), o REUNI tinha como diretrizes:

- Reduzir a taxa de evasão, principalmente no período noturno, com o objetivo de reduzir o número de vagas ociosas;

- Ampliar a mobilidade estudantil, cursos e programas de educação superior;

- Revisar a estrutura acadêmica, com o intuito de elevar a qualidade dos cursos;

- Diversificar as modalidades de graduação;

- Aumentar as políticas de inclusão e assistência estudantil;

- Possibilitar a articulação entre os níveis do Ensino Superior;

Assim, somando a fase anterior ao REUNI à fase já pautada pelo REUNI, tem-se a criação de 126 novos campi e de 14 novas Universidades Federais durante o período do Governo Lula, segue sua distribuição pelo país na Figura 3.

De modo similar ao usado na Figura 2. A Figura 3 mostra que os marcadores mais claros são os campi criados antes de 2003 e os marcadores mais escuros são os campi criados no período do Governo Lula. Ao analisar essa Figura percebe-se uma distribuição geográfica semelhante com a dos IFs porém, no caso dos campi universitários, parece que a distribuição é menos heterogênea que no gráfico dos IFs, principalmente na região Centro-Oeste, devido aos campi criados durante o século XX. Deste modo, aparenta não ter uma carência geográfica tão acentuada quanto a dos IFs (exceto, talvez, por alguns lugares da região Norte). 
Figura 3 - Campi universitários implantados até 2010

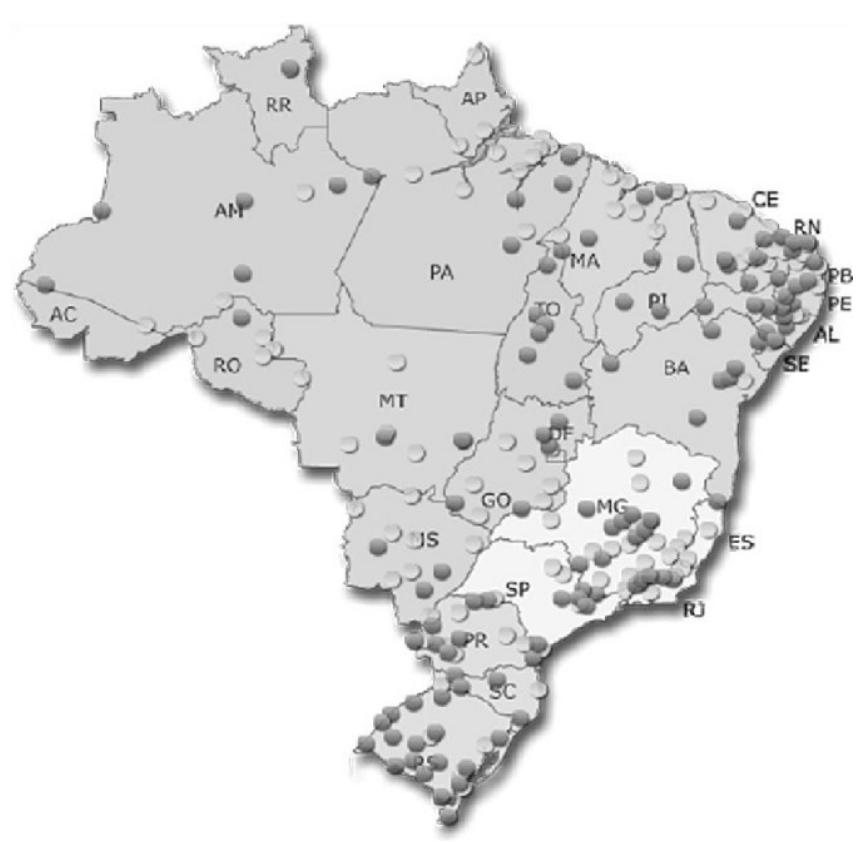

Fonte: MEC (2011)

\section{ESTUDO EMPÍRICO}

Esta seção trata da análise quantitativa do trabalho. Para que esta temática possa ser abordada com detalhes, a seção está divida nas três subseções a seguir.

\subsection{Base de dados}

Para cumprir com os objetivos já citados, foram coletados diversos dados econômicos e sociais de 5561 municípios brasileiros. Estes dados foram extraídos do censo de 2010, realizado pelo IBGE ${ }^{10}$, dentre esses dados temos:

- População total de cada município.

10 Disponível em https://censo2010.ibge.gov.br/ 
- Renda domiciliar per capita de cada município.

- Macrorregião, mesorregião e microrregião de cada município.

Além dos dados acima citados, calculou-se o PIB per capita de 2000 de cada município através de dados sobre a população (censo de 2000) e o PIB estimado de cada município no ano de 2000 realizado pelo IBGE ${ }^{11}$. Foram coletados, também, o ano de inauguração de cada campus e IF em cada município através de informações disponibilizadas pelo MEC e também o partido político de cada prefeito desses municípios, através de dados do TSE (Tribunal Superior Eleitoral). ${ }^{12}$

\subsubsection{Estratégia de especificação}

Uma primeira tentativa de estimar o efeito médio na probabilidade de um município ganhar um novo campus (durante o período de 2003 a 2010, devido ao fato do seu prefeito ser do partido da coligação federal durante o período em que o campus foi instalado) seria através dos seguintes modelos de regressão linear, tendo seus parâmetros estimados pelo método dos MQO (GUJARATI; PORTER, 2011, p.851).

$$
\begin{aligned}
\text { NewUni }_{i} & =\hat{\alpha}_{0}+\alpha^{\wedge}{ }_{1} \text { Aliado }_{i}+\varepsilon_{i} \\
\text { NewIF }_{i} & =\beta_{0}+\hat{\beta}_{1}{ }_{1} \text { Aliado }_{i}+\mu_{i}
\end{aligned}
$$

Em que NewUni é uma variável binária (dummy) que assume valor um para o município i, quando esse município recebe um novo campus universitário (federal) durante o período acima citado, e zero caso contrário. NewlF é uma variável binária que assume valor um quando o município i recebeu um Instituto Federal no período de análise, e zero caso contrário. Aliadoi também é uma variável binária que assume valor um quando o município i era governado por um prefeito do PT ou PMDB e zero caso contrário $\alpha^{\wedge} 0$, por sua vez, é o intercepto da equação 1a e mede a probabilidade média de um município ganhar um campus universitário, sendo que o prefeito do município i não seja dos partidos

11 O PIB dos municípios esta disponível em : <https://ww2.ibge.gov.br/home/estatistica/pesquisas/ pesquisa resultados.php?id pesquisa=46> e a população de cada município encontra-se disponível em: $<$ https://ww2.ibge.gov.br/home/estatistica/populacao/censo2000/>

12 Disponível em: <http://www.tse.jus.br/hotSites/estatistica2008/index.htm e <http://www.tse.jus.br/eleitoreeleicoes/eleicoes/eleicoes-anteriores/eleicoes-2004> 
do PT ou PMDB (categoria de referência). De maneira análoga $\hat{\beta}$ o mede a probabilidade média de um município i, cujo prefeito não seja do PT ou PMDB (categoria de referência), ganhar um novo Instituto Federal, $\varepsilon_{i}$ seria o resíduo da regressão 1a para o município i, $\mu_{i} \mathrm{O}$ resíduo da regressão $1 b$ para o município $i$, e os parâmetros $\hat{\alpha}_{1}$ e $\hat{\beta} \hat{1}_{1}$ medem os efeitos médios de um município ter seu prefeito dos partidos PT ou PMDB na probabilidade de um município conseguir um novo campus Universitário ou um novo Instituto Federal respectivamente ${ }^{13}$.

A ideia de se estimar o efeito pelo modelo 1 é clara já que, conforme é explicitado por Gujarati e Porter (2011), se ambos os modelos acima passarem em um teste de normalidade dos resíduos (Bera-Jarque, por exemplo) além das outras hipóteses clássicas do teorema de GaussMarkov ${ }^{14}$, então poderemos fazer um teste t nos parâmetros $\alpha_{1}{ }_{1}$ e $\hat{\beta}$. Caso os testes mostrem que um dos os parâmetros (ou os dois) são diferentes de zero com $\alpha \%$ de significância, então teríamos um indicativo de que com até $(1-\alpha) \%$ de confiança de que o fato de o município ter um prefeito dos mesmos partidos que os partidos no comando do Governo Federal causa um impacto significativo na probabilidade desse município receber um campus universitário (se $\alpha^{\wedge} 1$ der significante) ou um Instituto Federal (caso $\hat{\beta} \hat{1}_{1}$ dê significante).

Porém, há pelo menos três graves problemas no método de estimação das equações 1a e 1b. Primeiro, o fato de termos uma variável binária como variável dependente e estarmos tentando estimá-la com um modelo de probabilidade linear (MPL), faz com que se torne possível que a mesma assuma valores que $6 \subset$ no intervalo [0,1](WOOLDRIDGE,

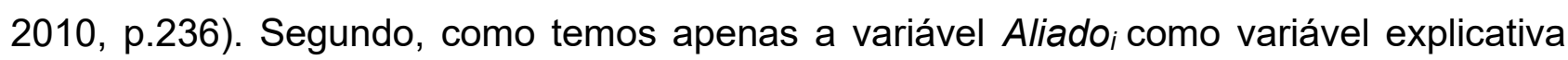
para ambos os modelos, é altamente improvável que não haja outra(s) variável(is) que influencie(m) na decisão do governo de implantar um novo campus universitário ou um Instituto Federal e que não esteja correlacionada com os partidos dos prefeitos, de modo mais formal, caso $\operatorname{Cov}(\varepsilon, A l i a d o) 6=0$ (ou $\operatorname{Cov}(\mu, A l i a d o) 6=0)$ e $\operatorname{Cov}(\varepsilon, N e w U n i) 6=0$ (ou

\footnotetext{
13 Vale lembrar que a probabilidade TOTAL média estimada de um município conseguir um novo campus universitário (considerando apenas a variável aliado) ou um Instituto Federal dado que a dummy aliado está

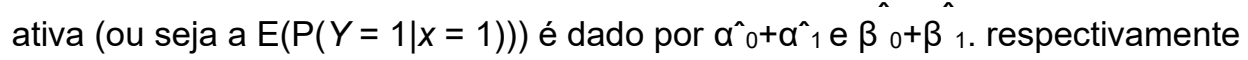

${ }^{14}$ A hipótese de normalidade foi frisada separadamente das demais hipóteses pois o teorema de GaussMarkov não precisa da hipótese de normalidade nos resíduos para que o estimadores continuem MELNV (Melhores Estimadores Lineares não Viesados). Contudo, é essencial para que o teste t possa ser aplicado, para mais detalhes ver (GUJARATI; PORTER, 2011, p.94)
} 
$\operatorname{Cov}(\mu$, NewIF) 6= 0) ocorra, temos que os estimadores serão inconsistentes, viesados e ineficientes, mesmo que o erro e a variável explicativa não fossem correlacionados, o intercepto ainda seria viesado ${ }^{15}$ (GUJARATI; PORTER, 2011, p.469-472). E por último, temse o problema da endogeniedade decorrente das duas equações, já que quando o Governo Federal concede um campus ou um IF para aquele município, provavelmente o fato de ele ganhar um campus universitário torna a probabilidade de ele ganhar um Instituto Federal maior (pois o município é maior, tanto economicamente, quanto em população e em influência política). Além disso, o fato de um município ser grande o suficiente para ganhar um Instituto, mas não o suficiente para ganhar um campus universitário e a decisão de implantar um campus ou implantar um IF serem tomadas de forma simultânea (dado os dados que temos disponíveis) indicam que a correlação entre $\varepsilon$ e $\mu$ é $6=0$. Se isso ocorre não podemos estimar as equações separadamente pois os parâmetros serão viesados, inconsistentes e ineficientes devido ao viés da simultaneidade (WOOLDRIDGE, 2010, p.515).

Dessa maneira, para contornar o primeiro problema, basta definir uma função de distribuição acumulada (f.d.a) para estimar as regressões, sendo essas os modelos logit e probit derivados de um modelo de variável latente, assim conseguimos garantir que a probabilidade de que a variável de interesse seja igual a 1 (no caso NewUni e NewIF) irá ficar obrigatoriamente no $[0,1]$. As mais conhecidas e usadas são a função logística ${ }^{16}$ e a função de densidade normal que dão origem (conforme dito anteriormente) aos modelos logit e probit respectivamente (WOOLDRIDGE, 2010, p.535-537).

Para contornar o segundo problema basta colocarmos variáveis de controle nas equações de maneira a tornar a estimação do efeito a mais fidedigna possível. Caso seja possível colocar todas as variáveis que possuam uma alta covariância com a variável Aliado e (principalmente) com as variáveis NewUni e NewIF nas regressões, de maneira a termos uma baixa covariância dos resíduos de cada regressão com as suas respectivas variáveis dependentes, então as estimativas estarão mais confiáveis. Para fazer a escolha dessas variáveis de controle, e aproveitando essa etapa do processo para tentar identificar o perfil dos municípios que possuem maior probabilidade de ganhar um novo campus e testar se

\footnotetext{
15 Esse é o problema do viés da variável omitida, amplamente discutido em manuais de econometria e microeconometria.

16 Usando o exemplo da logística, sendo $F^{(z)=\frac{\exp (z)}{1+\exp (z)}}$ dessa forma $0<F(z)<1$, já que para qualquer $z \in \mathrm{R}$ temos que quando $z \rightarrow \infty, F(z)=1$ e quando $z \rightarrow-\infty, F(z)=0$ (WOOLDRIDGE, 2010, p.536-537)
} 
esse perfil condiz com o perfil que o MEC se propôs a atender, colocaremos as variáveis que atendam as três dimensões propostas pelo MEC, sendo elas (MEC, 2011):

- Dimensão social: segundo o MEC, eles priorizariam municípios com mais de 80 mil habitantes e que tivessem renda per capita menor que 1000 reais.Com isso, foi criada uma dummy que assumiria valor um para todos os municípios que tivessem mais de 80 mil habitantes e uma renda domiciliar per capita menor que 1000 reais, e zero caso contrário.

- Dimensão Geográfica: teriam prioridade os municípios que tivessem mais de 50 mil habitantes e ainda não tivessem um IF ou um campus. Como forma de capturar esse fator (além da dummy citada no item anterior que, parcialmente, já traz esta dimensão incorporada), foi considerada uma dummy para a região Nordeste devido às idiossincrasias da região. Da mesma forma, foi acrescentada a variável dummy Nordeste $\cap$ Aliado para que se fosse possível identificar o efeito da variável Aliado nas demais regiões do país.

- Dimensão de desenvolvimento: teriam prioridade os municípios que estivessem próximos de grandes investimentos. Logo, como uma proxy desse fator foi usado o logaritmo natural do PIB per capita. Para evitar os problemas de endogeniedade referente ao fato da criação de um campus aumentar o PIB per capita, foi usado o logaritmo do PIB per capita do censo de 2000 ao invés do censo de 2010.

E por último, devido ao problema da endogeniedade e do viés de simultaneidade discutido anteriormente, é necessário estimar as duas equações simultaneamente de forma a amenizar o problema. Além disso, não é possível estimar as equações pelo método dos Mínimos Quadrados Ordinários, por isso, é necessário que se recorra ao método da Máxima Verossimilhança (WOOLDRIDGE, 2010, p.539). Devido a todos os motivos discutidos anteriormente o método para a estimação do efeito da variável Aliado será um modelo probit bivariado conforme especificado pelas equações abaixo:

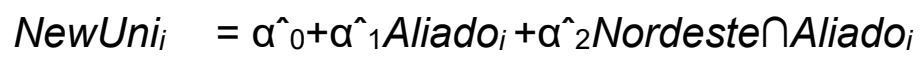

$$
\begin{aligned}
& +\alpha^{\wedge}{ }_{3} \text { Nordeste }_{i}+\alpha^{\wedge}{ }_{4} p o p \cap \text { renda }_{i}+\alpha^{{ }_{5}} \operatorname{Ln}(P I B p c)_{i}+\varepsilon_{i}
\end{aligned}
$$




$$
\begin{aligned}
& \text { NewlF } i=\hat{\beta}_{0}+\hat{\beta}_{1} \text { Aliado }_{i}+\hat{\beta}_{2} \text { Nordeste } \text { Aliado } i \\
& +\hat{\beta}_{3} \text { Nordeste }_{i}+\hat{\beta}_{4} \text { pop }_{\text {prenda }}+\hat{\beta}_{5} \operatorname{Ln}(P I B p c)_{i}+\mu_{i}
\end{aligned}
$$

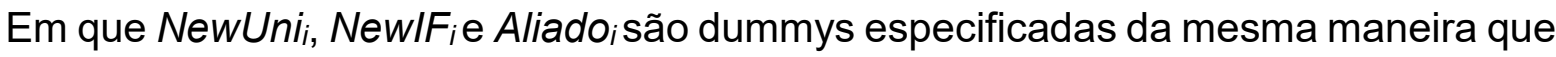
nas equações 1a e 1b, NordestenAliado; é uma dummy que assume valor um quando o município i é da região Nordeste e possui um prefeito do PT ou PMDB e zero caso contrário.

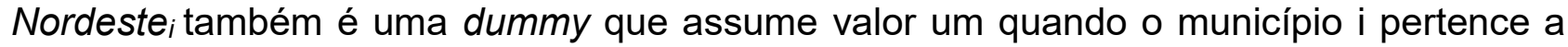

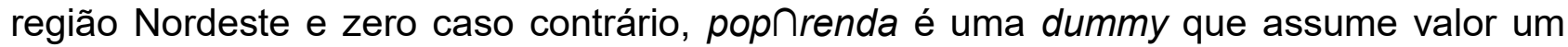
quando o município i possui mais de 80 mil habitantes e renda domiciliar per capita menor que mil reais simultaneamente e zero caso contrário. $L N(P I B p c)_{i}$ é o logaritmo natural do PIB per capita do município i, $\varepsilon_{i}$ é o resíduo da equação $2 a, \mu_{i}$ é o resíduo da equação $2 b$ e os $\hat{\alpha}_{j}$ e $\hat{\beta}$ são os parâmetros estimados do modelo.

Segue na figura 4 um exemplo meramente ilustrativo do biprobit: 
Figura 4 - Ilustração do biprobit

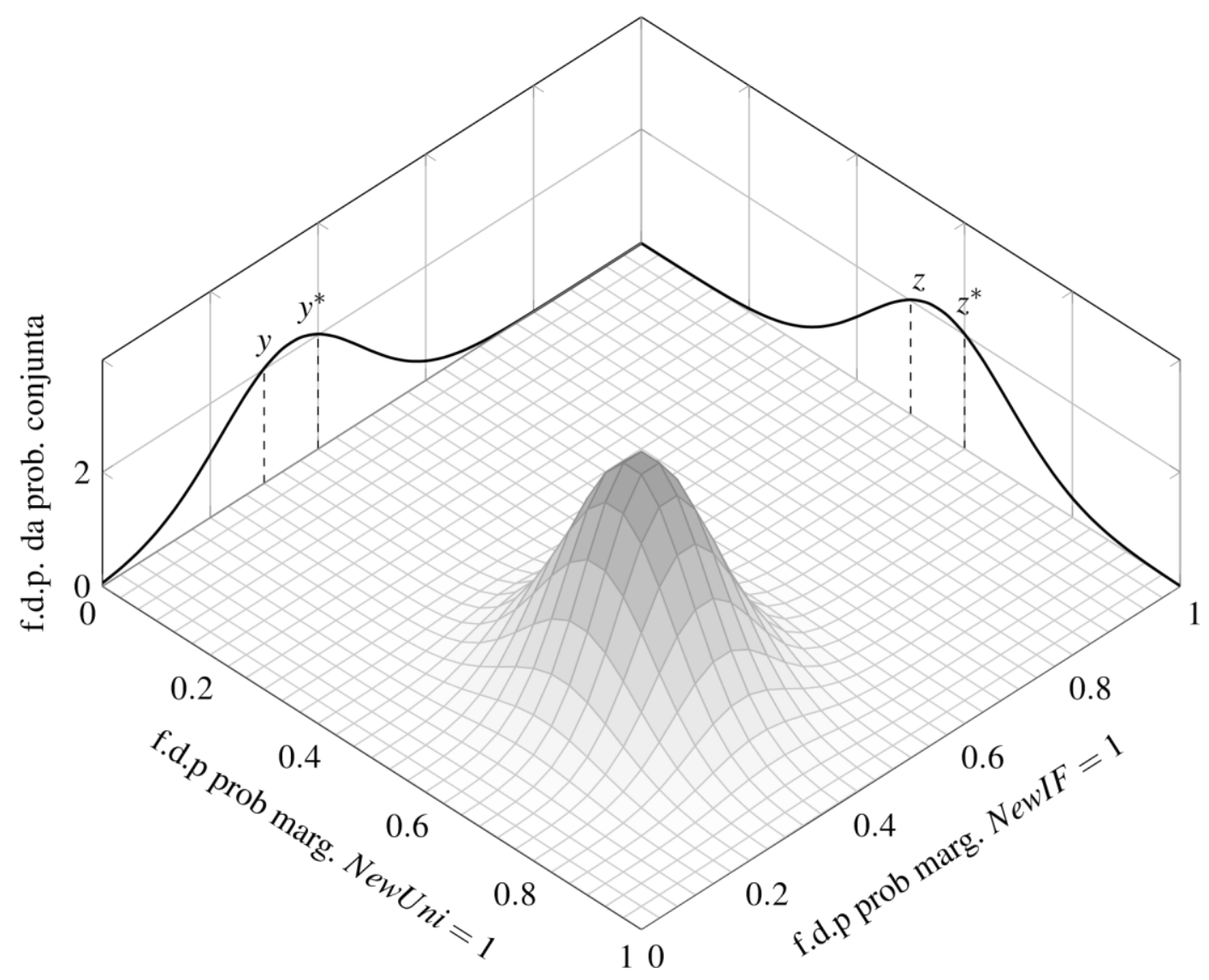

Fonte: Imagem meramente ilustrativa, elaborado pelos autores

Temos na Figura 4 uma ilustração da ideia do biprobit. Cada uma das equações 2 estimará o valor das variáveis aleatórias (v.a) que determinam as funções de densidade de probabilidade (f.d.p) marginais ( $z$ e $y$ ) e consequentemente também terá condições de estimar a f.d.p conjunta, já que seus parâmetros são determinados pelas médias e pelos desvios padrões das f.d.p marginais, além da covariância entre as v.a (de maneira mais rigorosa entre os resíduos de cada equação que estimam as v.a) de cada f.d.p (o Rho) ${ }^{17}$. Assim, também conseguimos estimar a probabilidade marginal de qualquer um dos municípios já que, como cada município terá um $z$ e um y estimado para si através do modelo, basta calcularmos a área da distribuição até o ponto gerado pelo modelo ${ }^{18}$. Contudo, caso o Rho dê diferente de zero, as análises precisariam ser feitas através da

\footnotetext{
17 Conforme ilustrado em Greene (2003)

18 Ou seja, fazer ady oudz, depende de qual probabilidade marginal se quer estimar.
} 
distribuição conjunta, será necessário o uso de uma integral dupla para estimar a probabilidade de tanto NewUni quanto NewIF assumirem um valor simultaneamente (pois a mesma se torna um volume, conforme ilustrado na figura 4).Dito isto, temos que, como o modelo estima o tanto o $z$ quanto o $y$, é possível ter uma estimativa do cálculo do impacto da variável Aliado na probabilidade de concessão de uma unidade. Basta olharmos a figura 4 , nela temos que $z^{*}-z=\hat{\alpha}_{1}$ e $y^{*}-y=\hat{\beta_{1}{ }^{19}}$, logo, o impacto na probabilidade marginal causado pela variável Aliado para cada caso é simplesmente a área entre as linhas tracejadas ${ }^{20}$. Porém, para ver o impacto sobre a distribuição conjunta é necessário que se tenha além dos parâmetros das distribuições marginais, a covariância entre as v.a (Rho).

Agora que se definiu como o modelo será especificado, é preciso verificar se há a necessidade de algum tratamento nos dados. De fato, é interessante excluirmos os municípios que já possuem um campus universitário, quanto um instituto, pois esses municípios possuem características bem distintas dos outros municípios, principalmente porque são muito mais populosos que a média dos municípios restantes (o que "obrigaria" o Governo Federal a colocar um Instituto ou uma universidade caso o município só tenha uma das duas). Dessa forma foram excluídos da amostra 48 municípios que possuíam tanto uma universidade quanto um Instituto, 63 municípios que já possuíam apenas um Instituto e 66 municípios que já possuíam apenas uma universidade conforme mostrado na tabela 1, assim a estimação foi feita com os 5384 municípios restantes.

\footnotetext{
${ }^{19}$ Vale lembrar que o impacto da variável Aliado é constante nas respectivas v.a (não na probabilidade e sim no valor da v.a), pois a variável Aliado é uma variável Dummy, caso não fosse, o impacto era variável pois teria que se considerar o valor assumido pela variável Aliado para que se estimasse a v.a e consequentemente a probabilidade (WOOLDRIDGE, 2010).

${ }^{20}$ Ou seja a $\mathrm{R}_{y}{ } * f(y) d y$ ou $\mathrm{R}_{z} z f(z) d z$
} 
Tabela 1 - Número de municípios com Institutos e Universidades federais antes de 2003 por região

\begin{tabular}{ccccc}
\hline Região & old IF Uni & old Uni & old IF & Total \\
\hline Norte & 9 & 14 & 5 & 28 \\
Nordeste & 15 & 12 & 22 & 49 \\
Sul & 11 & 6 & 11 & 28 \\
Sudeste & 8 & 22 & 18 & 48 \\
Centro Oeste & 5 & 12 & 7 & 24 \\
\hline Total & 48 & 66 & 63 & 177 \\
\hline
\end{tabular}

Fonte: Elaborado pelos autores.

Nota: old IF são os municípios que tinham apenas Instituto, old Uni os que tinha apenas Universidade e old IF Uni são os que já possuíam os dois, elaborado pelos autores

\section{Resultados obtidos}

De acordo com o que foi discutido na seção passada, segue na Tabela 2 os resultados do modelo especificado conforme as equações 2 .

Tabela 2 - Resultados do modelo probit bivariado

\begin{tabular}{|c|c|c|c|c|c|c|}
\hline \multirow[t]{2}{*}{ Variáveis } & \multicolumn{3}{|c|}{ New Uni } & \multicolumn{3}{|c|}{ New IF } \\
\hline & Parâmetros & $z$ & $P>|z|$ & Parâmetros & $z$ & $P>|z|$ \\
\hline Constante & $\begin{array}{c}-2.6219^{* * *} \\
(0.5733)\end{array}$ & -4.57 & 0.000 & $\begin{array}{c}-2.7404^{* * *} \\
(0.5240)\end{array}$ & -5.23 & 0.000 \\
\hline Aliado & $\begin{array}{c}0.1329 \\
(0.1070)\end{array}$ & 1.24 & 0.214 & $\begin{array}{c}0.2022^{* *} \\
(0.0873)\end{array}$ & 2.32 & 0.021 \\
\hline Nordeste haliado & $\begin{array}{c}0.0323 \\
(0.1965)\end{array}$ & 0.16 & 0.870 & $\begin{array}{l}-0.2309 \\
(0.1633)\end{array}$ & -1.43 & 0.152 \\
\hline Nordeste & $\begin{array}{c}0.0433 \\
(0.1307)\end{array}$ & 0.33 & 0.740 & $\begin{array}{l}0.2124^{* *} \\
(0.1054)\end{array}$ & 2.02 & 0.044 \\
\hline Pop $\cap r e n d a$ & $\begin{array}{r}1.1846^{* * *} \\
(0.1244)\end{array}$ & 9.53 & 0.000 & $\begin{array}{c}1.5031^{* * *} \\
(0.1054)\end{array}$ & 14.17 & 0.000 \\
\hline Ln(Pib pc) & $\begin{array}{c}0.0396 \\
(0.0607) \\
\end{array}$ & 0.65 & 0.514 & $\begin{array}{c}0.075 \\
(0.0556)\end{array}$ & 1.35 & 0.178 \\
\hline PseudoR2 & 0.09 & Rho & 0.4651 & P(Wald Rho) & 0.000 & \\
\hline Observações & 5384 & Wald chi2(10) & 252.22 & Pchi2 & 0.000 & \\
\hline
\end{tabular}

Nota: erros padrões robustos entre parênteses, um, dois e três asteriscos significam coeficientes significantes ao nível de significância de 0,1, 0,05 e 0,01 respectivamente, elaborado pelos autores 
Na tabela 2, temos que a coluna dos parâmetros representa o valor calculado de cada parâmetro $\hat{\alpha}_{j}$ e $\hat{\beta}$ do modelo, a coluna New Uni mostra os resultados da equação $2 a$ e a coluna New IF mostra os resultados da equação $2 b$. A coluna $z$, por sua vez, mostra o valor do teste z para cada parâmetro considerando que a hipótese nula do teste é de que o parâmetro é igual a zero. A coluna $\mathrm{P}>|\mathrm{z}|$ mostra o nível mínimo de significância com o qual a hipótese nula será rejeitada ( $p$ valor). O PseudoR2 é uma medida de ajuste do modelo calculada através dos logaritmos da Máxima Verossimilhança do modelo inteiro (o da tabela 2) e do modelo contendo apenas a constante como "variável explicativa"21(WOOLDRIDGE, 2010), Rho é uma variável que mede o grau de correlação entre $\varepsilon$ e $\mu$ e serve como uma medida para verificar se as equações poderiam ser medidas separadamente ou em conjunto. O P(Wald Rho) mostra o resultado do teste de Wald para verificar se esse parâmetro (Rho) é estatisticamente diferente de zero, o Wald chi2 (10) mostra o valor do teste de Wald para verificar se o modelo está bem ajustado (no caso está utilizando uma distribuição qui-quadrado com 10 graus de liberdade, ele possui a mesma ideia que um teste $\mathrm{F}$ em uma regressão linear), e Pchi2 mostra o $\mathrm{p}$ valor do teste de Wald de ajuste do modelo.

Analisando os parâmetros e seus respectivos testes z, percebemos que aparentemente o MEC cumpriu com o perfil pretendido na parte da dimensão social se observarmos a dummy pop renda, pois o parâmetro para a mesma deu positivo e estatisticamente significante com 99\% de confiança nas duas equações. Porém, o mesmo não pode ser dito para as demais dimensões pois seus parâmetros deram inválidos aos níveis de significância habituais (1\%,5\% e 10\%), com a exceção da dummy Nordeste para os IFs. Além disso, o efeito da variável aliado na probabilidade de o Governo Federal conceder um novo campus, se desconsiderarmos os campi que a região Nordeste recebeu, se mostra positivo nas duas equações, embora seu efeito na probabilidade de se conseguir um novo campus universitário não seja significativo aos níveis de significância usuais (1\%, $5 \%$ e $10 \%$ ), ele se mostra significativo na probabilidade de se conseguir um novo Instituto. Além disso, percebe-se que o PseudoR2 deu 0,09, apesar de ser aparentemente baixo, é comum de acontecer em modelos com variável dependente binária. O modelo "passa" no teste de Wald com mais de $99 \%$ de confiança, o que indica que o modelo está bem ajustado e o rho deu altamente significante o que corrobora a teoria de que os resíduos das duas

${ }^{21}$ Sendo o logaritmo da MV do modelo inteiro definido por a e o logaritmo da MV do modelo só com a constante definido por $b$, temos que $\operatorname{Pr} 2={ }^{(b-} b^{a)}$ 
equações não são independentes, sendo assim, realmente é necessário que se estime o modelo por equações simultâneas ${ }^{22}$. Com base nessas informações, percebemos que esse modelo tem indicativos de que pode ser usado para estimar a probabilidade de um município ganhar novos campi.

Entretanto, a análise dos parâmetros dos resultados do modelo só é suficiente para determinarmos a direção do impacto das variáveis na probabilidade mas não sua intensidade, ou seja, apenas se quando a variável aumenta isso causa um aumento ou redução na probabilidade de conseguir um novo campus e se esse efeito é estatisticamente diferente de zero ${ }^{23}$, sendo que essa informação só é possível de ser extraída pois faz parte da definição de uma f.d.a que, se $z>z^{*}$ então obrigatoriamente $F(z) \geq F\left(z^{*}\right)$ no caso de uma função univariada e $F(y, z) \geq F\left(y, z^{*}\right)$ no caso de uma distribuição bivariada (HSU, 1996), ou seja, uma f.d.a é sempre não decrescente ${ }^{24}$, isso porque as variáveis dependentes do modelo não são os $F(y, z), F(y)$ ou $F(z)$ diretamente e sim o $z$ ou o $y^{25}$. Assim sabemos a direção do impacto mas não sua intensidade, para termos condições de estimar o valor do impacto (ou seja o valor de _ $\partial_{\partial x}{ }^{p}$ sendo $x$ uma variável explicativa qualquer do modelo) precisamos fazer uma regra da cadeia, ou seja, ver o impacto de $x$ em $z$ (ou $y$ ) para então ver o impacto da variação de $z$ (ou y) em $F(z)$ (ou $F(y))$ se quisermos o impacto sobre a função marginal ou sobre $F(y, z)$ se quisermos o impacto sobre a distribuição bivariada. A forma de se calcular essa variação (na distribuição marginal), considerando $x$ como a variável dummy Aliado e $p$ a probabilidade de o município ganhar um Instituto Federal (por exemplo), está descrita na 3 equação

$$
\frac{\partial p(I F=1)}{\partial \text { aliado }}=\left[F\left(\hat{\beta_{0}}+\hat{\beta_{1}}+\ldots+\hat{\beta_{5}} \operatorname{Ln}(P I B p c)\right)\right]-\left[F\left(\hat{\beta_{0}}+\ldots+\hat{\beta_{5}} \operatorname{Ln}(P I B p c)\right)\right]
$$

Assim percebemos que o efeito na probabilidade não depende apenas do valor do $\hat{\beta}{ }_{1}, e$ sim, de todas as outras variáveis explicativas e parâmetros do modelo. Devido a isso, o efeito na probabilidade vai variar com o perfil do município, ou seja, caso o município já

\footnotetext{
${ }^{22}$ Caso o rho desse insignificante aos níveis de significância usuais, ele funcionaria como um teste de endogeniedade de Haussman, para mais detalhes ver (CAMERON; TRIVEDI, 2010)

${ }^{23}$ Ou seja, se ${ }^{2}{ }^{2} \partial_{x}{ }^{p}>0$ ou $<0$ sendo $x$ uma variável explicativa do modelo e $p$ a probabilidade da variável dependente ser igual a 1.

${ }^{24}$ Como estamos fazendo um modelo probit bivariado, a f.d.a usada é uma normal bivariada que é sempre crescente, logo, olhar para o modelo diretamente é possível para determinar a direção do impacto

${ }^{25}$ Aonde $F(z) e F(y)$ são as probabilidades marginais de se um município receber um Instituto Federal e uma Universidade respectivamente
} 
possua características que façam com que a probabilidade de ele ganhar um Instituto seja maior, isso faz com que o fato de ele possuir um prefeito aliado com o Governo Federal cause um impacto maior do que com o município que não possua essas características. Isso ocorre porque como a $F(z)$ é uma normal univariada e o valor da constante do modelo é substancialmente negativo, faz com que municípios que não possuam as características que ativam as dummys, que possuem parâmetros positivos, e tenham um baixo PIB per capita, faz com que eles fiquem na "cauda esquerda" da distribuição, assim o acréscimo em z e consequentemente em $F(z)$, causado pela variável Aliado, é menor do que em um município que está mais próximo da média da distribuição. Porém, é importante mensurar o efeito da dummy Aliado $;$ em cada situação, ou seja, o quanto ela impacta na probabilidade de concessão de um campus do REUNI ou CEFET, mas também o quanto isso impacta na probabilidade conjunta de um município possuir um campus de um dos programas e não possuir do outro, ou de possuir ambos os campi. Essa análise não é possível apenas com os impactos sobre as distribuições marginais pois, conforme ilustrado por Hsu (1996) precisaríamos supor independência entre $z$ e y para que $F(y, z)=F(y) F(z)$ fosse verdadeiro e temos indicativos de que essa afirmação é falsa pois o rho deu estatisticamente diferente de zero. Assim, este cálculo foi feito pegando a média de todas as previsões do modelo, ou seja a $E\left(P^{\wedge}\right)$ ) para cada uma das quatro situações possíveis (New Uni $=1$ e New IF = 1 , New Uni $=1$ e New IF = 0, New Uni $=0$ e New IF = 1 e New Uni $=0$ e New IF =0), para os municípios que eram aliados ou não, e também para os municípios que eram aliados ou não mas desconsiderando-se os municípios da região Nordeste. Foi usada a média das previsões (ou seja a $E\left(P^{\wedge}\right)$ ) por dois motivos. Primeiro, caso fossem feitas as previsões sobre as $\mathrm{E}(x)$ de cada variável do modelo, tenderíamos a cair na média da distribuição, o que faria o impacto da variável Aliado; sobre as distribuições marginais e sobre a distribuição conjunta ser maximizado (já que o Rho deu positivo e estatisticamente maior que zero). Assim, ao fazer o cálculo sobre a média das previsões ao invés da previsão sobre a média, conseguimos ter uma melhor estimativa do efeito médio da variável Aliado ${ }_{i}$ sobre a probabilidade de concessão dos campi.Segundo, é difícil que o valor médio de cada variável consiga representar um município, ou um grupo de municípios, pois temos dummys no modelo. Por exemplo, não se tem como representar o município que ficou na média da dummy Nordeste, pois ou os municípios estão na região Nordeste ou não estão (WOOLDRIDGE, 2010). Dito isso, considerando NewUni $=i$ e NewIF $=j \operatorname{com} i=0,1$ e $j=$ 0,1 , calculou-se a diferença entre as probabilidades estimadas conforme a equação 4 . 


$$
\Delta \mathrm{E}\left(\mathrm{P}^{\wedge}(\text { i } j \mid \Delta \text { aliado })\right)=\mathrm{E}\left(\mathrm{P}^{\wedge}(\text { i } j \mid \text { aliado }=1)\right)-\mathrm{E}\left(\mathrm{P}^{\wedge}(\text { i } j \mid \text { aliado }=0)\right) .
$$

Na equação 4 temos a variação na probabilidade, ou seja, o impacto causado na probabilidade devido ao município ter seu prefeito como aliado (tanto no caso com o Nordeste ou sem a região Nordeste). Vale lembrar que cada probabilidade que dá origem à diferença é a média das previsões feitas pelo modelo descrito na tabela 2, dado que os municípios que participam do cálculo da média da previsão respeitam as condições dadas pela dummys Aliado; considerando todas as regiões, e os que respeitam as condições da dummy desconsiderando a região Nordeste ${ }^{26}$. Segue abaixo a tabela com o cálculo da probabilidade média considerando todas as regiões:

Tabela 3 - Calculo da $E\left(P^{\wedge}((U n i=i l F=j))\right.$ considerando-se todas as regiões

\begin{tabular}{cccccc}
\hline & Não Aliado & \multicolumn{2}{c}{ Aliado } \\
\hline \multicolumn{4}{c}{ New IF = j } \\
New Uni = i & 0 & 95,60 & 2,76 & 94,33 & 3,43 \\
& 1 & 1,14 & 0,51 & 1,53 & 0,71
\end{tabular}

Nota: valores em porcentagem, elaborado pelos autores

Analisando a tabela 3, percebe-se que os valores correspondem, em certa medida, aos valores esperados, já que é esperado que o valor de $\mathrm{E}\left(\mathrm{P}^{\wedge}(\right.$ Uni $\left.=0 / F=0)\right)(95,60 \%$ e $94,33 \%$ para os não aliados e aliados respectivamente) seja elevado pois temos muitos municípios na amostra (5384) e poucos municípios (258) que receberam pelo menos um campus no período analisado e não possuíam nenhum dos dois antes de 2003 (pois esses municípios foram excluídos da amostra antes da estimação do modelo, conforme dito no último parágrafo da seção 3.2). Percebe-se, também, que o valor da probabilidade referente a receber apenas um campus do CEFET, ou seja a $E\left(P^{\wedge}(\right.$ Uni $\left.=0 / F=1)\right)$, é maior do que a probabilidade de se conseguir apenas um campus do REUNI, ou seja a $\mathrm{E}\left(\mathrm{P}^{\wedge}(\right.$ Uni $=1 / F=$

\footnotetext{
${ }^{26}$ Lembrando que quando se prevê o valor "bruto" da regressão para o município i esse valor é colocado na distribuição conjunta acumulada para que se tenha a estimativa da probabilidade. Por exemplo, caso o modelo preveja o valor $\mathrm{IF}^{*}=1,5$ e UNI $=0,5$ para o município i, logo, a $\mathrm{P}^{\wedge}(U n i=i I F=j)=\mathrm{F}(0.5,1,5)$, aonde $\mathrm{IF}^{*}=z$ $U \mathrm{NI}^{*}=y$ e $F(y, z)$ é a distribuição bivariada.
} 
0)) (sendo elas $2,76 \%$ e $1,14 \%$ para os não aliados e 3,43\% e 1,53\% para os aliados respectivamente), o que condiz com as expectativas já que a estrutura de um campus universitário é mais custosa do que a de um campus do CEFET. Assim, há municípios que não teriam a necessidade de ter um campus do REUNI no período analisado devido as idiossincrasias da região, porém, eram suficientes para a concessão de um campus do CEFET, da mesma forma que a probabilidade de um município "ganhar"os dois campus simultaneamente, ou seja a $\mathrm{E}\left(\mathrm{P}^{\wedge}(\right.$ Uni = $\left.1 / F=1)\right)$, foi a mais baixa de todas $(0,51 \%$ e $0,71 \%)$, pois é esperado que apenas as regiões com uma maior necessidade dessa implementação, devido as suas características socioeconômicas, sejam agraciadas com os dois campi.

Os cálculos referentes a probabilidade, desconsiderando os municípios da região Nordeste, estão na tabela 4.

Percebe-se, ao analisar a tabela 4, que os valores desta tabela possuem características semelhantes aos da tabela usada para o país inteiro porém, percebe-se alguma mudança quando são confrontadas suas respectivas diferenças calculadas através da equação 4. Segue o cálculo na tabela 5 abaixo:

Tabela 4 - Calculo da $E\left(P^{\wedge}(U n i=i I F=j)\right)$ desconsiderando a região Nordeste

\begin{tabular}{cccccc}
\hline & Não Aliado & \multicolumn{2}{c}{ Aliado } \\
\hline \multicolumn{4}{c}{ New IF $=\mathrm{j}$} \\
New Uni = i & 0 & 95,82 & 2,52 & 93,98 & 3,74 \\
& 1 & 1,17 & 0,49 & 1,50 & 0,78
\end{tabular}

Fonte: Elaborado pelos autores.

Nota: valores em porcentagem, elaborado pelos autores

Tabela 5 - Diferença na $E\left(P^{\wedge}(U n i=i l F=j)\right)$ causada pela dummy aliado, com e sem a região Nordeste

\begin{tabular}{cccccc}
\hline \multicolumn{3}{c}{ New IF = j } \\
\hline & \multicolumn{3}{l}{ Com } & \multicolumn{2}{l}{ Sem } \\
& Nordeste & \multicolumn{3}{l}{ Nordeste } \\
New Uni = i,j & $0-$ & 1 & $0-$ & 1 \\
& 0 & 1,27 & 0,67 & 1,84 & 1,22 \\
& 1 & 0,39 & 0,21 & 0,33 & 0,29
\end{tabular}

Fonte: Elaborado pelos autores. 
Nota: valores em p.p calculados através da equação 4, elaborado pelos autores

$\mathrm{Na}$ tabela 5, temos a diferença média estimada na probabilidade causada pela variação da dummy Aliado ${ }$, ou seja, quantos p.p se aumenta (ou diminui), em média, na probabilidade de ganhar um dos campi, ou ganhar os dois campi, ou não ganhar nenhum, devido ao fato do município ter o seu prefeito pertencente a um partido aliado a coligação federal. Dito isso, percebe-se que tanto com todas as regiões do país, quanto desconsiderando a região Nordeste, o efeito da variável Aliado; na probabilidade de concessão de pelo menos um campus é positivo, indicando que o mesmo influencia na decisão de concessão dos campi pelo Governo Federal. Porém, destaca-se o alarmante aumento substancial na diferença da probabilidade de concessão de apenas um campus do CEFET, ou seja um aumento na $\Delta E\left(P^{\wedge}(U n i=0 I F=1)\right)$, quando desconsidera-se a região Nordeste, apesar de o valor de 0,67 p.p passar para 1,22 p.p parecer pouco, vale lembrar que, como temos muitos municípios na amostra que não receberam um campus em comparação com os que receberam, um impacto estimado de 1,22 p.p é relativamente considerável.

\section{CONSIDERAÇÕES FINAIS}

Durante o primeiro governo petista (2003 a 2010) houve uma rápida expansão de unidades de ensino (tanto tecnológico quanto do ensino superior) promovida através dos programas do CEFET e do REUNI que faziam parte de todo o projeto de expansão das unidades educacionais no seu governo e posteriormente continuado no governo Dilma Rousseff. Esta expansão era pautada por uma necessidade dessas unidades em regiões necessitadas do país (MEC (2011)), porém, sabe-se que houve um aumento da concessão dessas unidades (principalmente os IFs) na Fase II da política de expansão, devido a possíveis pressões políticas dos governos regionais para o Governo Federal. com base nisso, esse trabalho buscou verificar se houve influência do "capital político" desses comandantes regionais na probabilidade de concessão dessas unidades, sendo esse "capital político" mensurado no seguinte trabalho, pelo partido político do prefeito do município. Ao testar esta hipótese através de um modelo probit bivariado, verificou-se uma influência positiva, mas não significante, estatisticamente falando, do impacto dessa variável na probabilidade de concessão das unidades. Entretanto, ao "desconsiderar" os 
municípios da região Nordeste, foi encontrado um impacto significante do partido político do prefeito na probabilidade de concessão dos IFs nos municípios das demais regiões do Brasil, com um intervalo de confiança de mais de $97 \%$, cujo valor médio estimado é de 1,22 p.p, logo, indicando que a decisão de implementação dos IFs tem como um dos fatores determinantes as "relações políticas" entre os governos municipais e o Governo Federal.

Além disso, é possível que o efeito não tenha dado significante para os dois tipos de unidades no país todo, ou para os IFs quando comparado apenas nos municípios fora da região Nordeste, por falta de uma (ou mais) covariada(s) não identificada(s) pelo pesquisador. Outra possibilidade é as dos municípios com pouco "capital político"(por terem menor importância econômica e política individualmente) se apoiarem com um município maior da sua microrregião para que o IF, ou até mesmo um campus seja implementado neste município maior, ou seja, os municípios fariam um lobby para que a unidade fosse para um município diferente do deles, este fator não consegue ser capturado pelo presente modelo, possibilitando que estudos futuros façam a mesma análise do presente trabalho, agregando os municípios em microrregiões.

Além das limitações anteriores, cabe fazer uma ressalva prudente: uma análise econométrica não se propõe a determinar as relações causais e sim apontar indícios das mesmas. Toda a análise feita é sempre indicativa e são tomadas medidas de forma que a evidência fique a mais crível e fidedigna possível, porém, ainda são indícios.

Por último, tem-se uma possibilidade para estudos futuros fazerem a mesma análise proposta neste trabalho, porem considerando os lobbys microrregionais na estimação.

\section{REFERÊNCIAS}

BARBOSA, M. P.; PETTERINI, F. C.; FERREIRA, R. T. Avaliação do impacto da política de expansão das universidades federais sobre as economias municipais. In: ANPEC-

ASSOCIAÇÃO NACIONAL DOS CENTROS DE PÓSGRADUAÇÃO EM ECONOMIA [BRAZILIAN ASSOCIATION OF GRADUATE PROGRAMS IN ECONOMICS]. Anais do $X L I I I$ Encontro Nacional de Economia [Proceedings of the 43rd Brazilian Economics Meeting]. [S.I.], 2016.

BRASIL. Decreto n 6.094. [S.I.]: Ministério da Educação, Abril, 2007.

BRASIL. Decreto n 6.096. [S.I.]: Ministério da Educação, Abril, 2007.

BRASIL. Lei no 8.948. [S.I.]: Ministério da Educação, Dezembro, 1994. 
BRASIL. Lei no 11.892. [S.I.]: Ministério da Educação, Dezembro, 2008.

BRASIL. Decreto no 4.048. [S.I.]: Ministério da Educação, Janeiro, 1942.

BRASIL. Decreto no 8.621. [S.I.]: Ministério da Educação, Janeiro, 1946.

BRASIL. Decreto $n^{\circ}$ 8.622. [S.I.]: Ministério da Educação, Janeiro, 1946.

BRASIL. Lei no 11.195. [S.I.]: Ministério da Educação, Novembro, 2005.

CAMERON, A. C.; TRIVEDI, P. K. Microeconometrics using stata. [S.I.]: Stata press College Station TX, 2010. v. 2.

CIAVATTA, M.; RAMOS, M. Ensino médio e educação profissional no brasil: dualidade e fragmentação. Retratos da Escola, v. 5, n. 8, p. 27-41, 2012.

FLORAX, R. J. The university: a regional booster? economic impacts of academic knowledge infrastructure. 1992.

GREENE, W. H. Econometric analysis. [S.I.]: Pearson Education India, 2003.

GUJARATI, D. N.; PORTER, D. C. Econometria Básica-5. [S.I.]: AMGH Editora, 2011.

HADDAD, F. O Plano de Desenvolvimento da Educação: razões, princípios e programas. [S.I.]: MEC-Ministério da Educação, INEP-Instituto Nacional de Estudos e Pesquisas Educacionais Anísio Teixeira, 2008.

HSU, H. P. Theory and problems of probability, random variables, and random processes. [S.I.]: McGraw-hill New York, 1996.

KUENZER, A. Z. A educação profissional nos anos 2000: a dimensão subordinada das políticas de inclusão. Educação e Sociedade, SciELO Brasil, v. 27, n. 96, p. 877-910, 2006.

LUCAS, R. On the mechanisms of development planning. Journal of Monetary Economics, v. 22, n. 1, p. 3-42, 1988.

MARTINS, C. B. O ensino superior brasileiro nos anos 90 . São Paulo em perspectiva, SciELO Brasil, v. 14, n. 1, p. 41-60, 2000.

MARTINS, C. B. A reforma universitária de 1968 e a abertura para o ensino superior privado no brasil. Educação \& sociedade, SciELO Brasil, v. 30, n. 106, 2009.

MEC. Um novo modelo em educação profissional e técnologica: Concepção e Diretrizes. Ministerio da Educação, 2010. Acessado em Outubro de 2017. Disponível em: <http://portal.mec.gov.br/index.php?option=com_docman\&view=download\&alias= 6691-ifconcepcaoediretrizes\&Itemid=30192>.

MEC. Expansão da educação superior e profissional e tecnológica: mais formação e oportunidades para os brasileiros. Ministério da Educação, 2011. Acessado em

Outubro de 2017. Disponível em:

<http://portal.mec.gov.br/expansao/images/APRESENTACAO_

EXPANSAO_EDUCACAO_SUPERIOR14.pdf>. 
MEC. Análise sobre a Expansão das Universidades Federais 2003 a 2012. Ministerio da Educação, 2013. Acessado em Outubro de 2017. Disponível em:

<http://portal.mec.gov.br/ docman/janeiro-2013-pdf/12386-analise-expansao-universidadefederais-2003-2012-pdf>.

MEC/SETEC, S. da Educação Profissional e T. Prestação de contas ordinárias anual: relatório de gestão 2010. [S.I.], 2011.

ROLIM, C.; KURESKI, R. Impacto econômico de curto prazo das universidades federais na economia brasileira. In: XIII Regional Economic Meeting (South ANPEC). Porto Alegre-RS, August. [S.I.: s.n.], 2010. p. 11-13.

ROMER, P. M. Endogenous technological change. Journal of political Economy, The University of Chicago Press, v. 98, n. 5, Part 2, p. S71-S102, 1990.

SAMPAIO, H. Evolução do ensino superior brasileiro. São Paulo, NUPES, Documento de Trabalho, v. 8, p. 91, 1991.

SOARES, M. d. J. A. As escolas de aprendizes artífices-estrutura e evolução. In: Fórum Educacional. [S.I.: s.n.], 1982. v. 6, n. 3, p. 58-92.

SOUZA, J. G. de. Evolução histórica da universidade brasileira: abordagens preliminares. Revista de Educação PUC-Campinas-ISSNe 2318-0870, n. 1, 2012.

TAVARES, M. G. Evolução da rede federal de educação profissional e tecnológica: as etapas históricas da educação profissional no brasil. 2012.

TEIXEIRA, A. Ensino superior no Brasil: análise e interpretação de sua evolução até 1969. [S.I.]: Editora UFRJ, 2005. v. 10.

WOOLDRIDGE, J. Introdução à econometria: uma abordagem moderna. São Paulo:

Cengage Learning, 2011. [S.I.]: APÊNDICES, 2010. 